\title{
FARMERS' MARKETS AS A BUSINESS MODEL ENCOURAGING SUSTAINABLE PRODUCTION AND CONSUMPTION
}

\author{
Ekaterina Arabska \\ University of Agribusiness and Rural Development - Plovdiv, Bulgaria
}

The current study discusses the role and the importance of alternative food networks, farmers' markets in particular, for sustainable rural development through the example of Bulgaria. Farmers' markets are considered as a sustainable business model of networking which encourages production and consumption of local food of healthy origin adhering to high standards for quality and safety, building society and trust and encouraging development of rural regions. The case of Bulgaria is scrutinized in the context of the support for local food and short supply chains anticipated under the national rural development programme for the period 2014-2020 and the current state-of-art and capacities of available farmers' markets. Some good practices are analyzed and presented establishing a new type of relationships between producers and consumers of farm products proving that farmers' markets could be efficient incubators of local businesses and new relationships with endusers. Conclusions are made on nature, objectives and functioning of farmers' markets, challenges and problems in their promotion, support and encouragement.

Keywords: sustainable development, alternative food networks, short supply chains, farmers' markets

With the global transition to a high energy consumption lifestyle, natural resources are exhausted, and the pressure on food production systems is boosted. The growing population and the change in consumer behavior lead to the emergence of a food economy characterized by large industrial production systems, which are environmentally unstable, socially unfair and even exploitative (Tozer, 2013). These conventional food systems are very dependent on access to cheap and abundant energy sources that can not be guaranteed in the long run. In the processes of raising awareness in the whole world about the importance of sustainable development, new approaches and initiatives in the development of a more sustainable agrifood chain assuring quality and safety of foods and products gain momentum.

The places for "alternative" food production and consumption have been the subjects of the growing interest among researchers and policymakers in recent years (Bos and Owen, 2016). Examples of such Alternative Food Networks (AFNs) are farmer's markets, community-supported agriculture (CSA), farm stores and others where food products carry social and spatial information that distinguishes them from the conventional agrifood systems The shorter, more transparent, more localized supply chains that characterize alternative food networks are based on the idea of linking / relinking as a fundamental set of biological, social and moral processes which provide opportunities for all the stakeholders to participate in ethical and transparent systems in which they are more tightly connected to each other and to the environment (Bos and Owen, 2016).

Alternative food networks are seen as a response to the food crisis and as a promising basis for a new food chain based on the sustainable development paradigm (Matacena, 2016). Their activities aim at realizing a process of relocation and resocialization of production, distribution and consumption practices, aiming at building a greener / environmentally friendly, socially equitable and economically sustainable food system. Alternative food networks cover different food supply and sale practices that differ from the main food systems and are based on three key concepts: accessibility (both for sale and for agricultural and food products); sustainability (in economic, social and environmental terms); quality and links between participants (Barbera and Dagnes, 2016).

Alternative food networks are defined from the point of view of short supply chains as initiatives and practices with potential for contributing to sustainable rural development at times when the crisis in conventional intensive agriculture is increasingly emerging and consumer pressure is increasing variety for food products of "different" quality (Renting et al., 2003). As part of the alternative food networks, farmers' markets are characterized as trading venues for low-volume food producers in order to "retain" part of the value of output lost in conventional food systems (Tozer, 2013). Farmer markets are described as a social phenomenon for the transition to sustainable development. Farming markets are seen as incubators for new businesses each year taking the full sales value of their products by jumping intermediaries. They continue to grow in number, in terms of sales volume and season length. Farmer markets, however, are far more than places to sell food, and they have become major public institutions - places for meetings and social interactions, a well-established marketing system with great potential for sustainable development.

The goal of the study presented is to outline the main characteristics of farmers' markets as a sustainable business model and their potentials to contribute to development of rural regions in different ways through the unique opportunities for a new type of interactions between producers and counsumers and encouragement of sustainable production and consumption. Aiming at making that, the research presents case studies from Bulgaria as an example of a country trying to provide support through the national rural development programme. 


\section{Material and methods}

Current study makes analyses of farmer's markets as parts of the concept of alternative food networks and short supply chaines and as tools for sustainable rural development. Presented are the prerequisites and problems for their development in Bulgaria. Information and data from the rural development programme of the country for the period 2014-2020 are used, as well as the results of a preliminary investigation of the Ministry of Agriculture, Food and Forestry on the conditions for the implementation of the measures planned. Through the example of several case studies of really functioning and successful invitiatives in the field the common features of farmers' markets are concluded and recommendations for future development are provided.

\section{Results and discussion}

The first category of short food supply chains (farm shops, farm markets, roadside sales, boxing, home delivery, e-mail, e-commerce) is essentially based on "face-to-face" interactions as a networking mechanism for producers and consumers. Consumers buy products directly from the producer / processor, and authenticity and trust are mediated through personal interactions. This category broadly coincides with the narrower definition of direct sales, but can somewhat expand through the use of the Internet, but in the main it remains limited to individual farms. The second category (groups of farm shops, consumer cooperatives, CSA, events, restaurants, tourism enterprises, catering to institutions, etc.) goes beyond direct interactions and is basically based on the proximity links. Expanding short food chains over longer distances implies building more sophisticated institutional arrangements. Food networks are mainly based on spatial proximity where products are sold in the region or the place of production, and consumers are familiar with the "local" nature of the product at the point of sale. The organization of activities events, fairs, thematic routes, etc. can contribute to the regional identity of products, attract customers and encourage the development of the network. Such networks may also be based on cultural proximity. The third category (certification marks, product codes, reputation effects) further broadens the breadth of short food chains to wider time and space relationships, where products are sold to consumers outside the region of production and who may not have a personal connection at all and presence in this region. However, they are still considered to be "short" food supply chains - not the distance to which the product is transported is decisive, but the fact that it has value and information that reaches the user, allowing the consumer to carry out "the connection" with the place of production, the understanding and the values of the people and the production methods used. Namely, the successful transmission of information allows products to be distinguished from "anonymous" goods and to impose a "special" price if the information in them is considered valuable to the consumer (Renting et al., 2003).

\section{Farmers' markets as incubators of local businesses for sustainable rural development}

A farmer's market start guide ${ }^{1}$ (2005) states that today farmers' markets are seen as a solution to the multifaceted problem of growing isolation in modern society and culture - isolation from others, environment and food sources. That is why people perceive them as a place to gather families, neighbours and friends; an environment where inspirational

1 Starting a new farmers market. 2005. D. Jolly (Ed.). The Farmers Market Management Series, Volume 1. UC Small Farm Center. connections can be established and close to their roots. The growth and success of the farmers' markets impresses, but very often the concept itself takes different forms. What is distinctive, however, is related to the following main points: offering local food (produced on a particular territory); sales directly from the manufacturer (someone who is directly involved in the production / processing); functioning in accordance with local law and standards.

The main aspects leading to the success of the farmers' markets are set out in a report ${ }^{2}$ on how to sell successfully on farm markets (2009): quality (fresh, clean and delicious food produced with care), fair prices (user-friendly and bearing enough profit and competitiveness for the producer), appropriate advertising (raising consumer confidence), high-level hygiene (including assurance of food tasting), vendor's behaviour (courtesy and respect to the client to ensure his/her loyalty). Added to this is the appropriate visualization and intriguing information (including the encouragement of discussions), the formation of one's own identity (for good product recognition and building strong relationships with clients), conversations with clients and establishing loyal relationships / partnerships, planning and entertainment (Pierson, 2009).

Starting a farmer's market is a major challenge, taking into account various factors and activities related not only to the physical establishment of the farmer's market but also to issues related to its administration and management so as to ensure its development and vitality (Mainville, 2010). The following six key points have been identified: establishment of a management body, acceptance of a mission, formulation of objectives, adoption of rules, development of rules, defining the role of the market manager.

Surveys on the consumer profile of farm goods and their advantages highlight quality and price as the most important factors (Wolf et al., 2005), social relationships and more sustainable behavior (Bos and Owen, 2016), as well as intangible factors - perceived customer-company-territory interaction (CCTI) (Cassia et al., 2012), but also address key problem areas such as accessibility and convenience (Wolf et al., 2005), uncertainty regarding information (price and product), supply and quality (Pascucci et al., 2016). The latter raise questions about the mechanisms for functioning and participation in such initiatives (Pascucci et al., 2016), the overcoming of different barriers (regulatory regimes, logistical and operational issues) and the importance of building local food policies related to other policies of sustainable and balanced territorial development (Matacena, 2016).

Indifferentfood supply chains, consumers have different understandings of quality, in some cases "hard" or "soft" ways of perception, but generally things that are familiar, easy to sense and find. In traditional local markets and farmers' markets, the overall concept of "hard" quality (prices, standards, brands) prevails, whereas multiple concepts of "soft" quality (traditions, trust, environment, local communities and products) take different forms (Barbera and Dagnes, 2016). This shows how difficult it is to give a definition of quality, but "soft" quality is definitely of greater importance in alternative food networks than in large food chains, although there consumers also share their idea and demands, but its manifestations are tangible precisely in nontraditional systems characterized by spatial, economic and / or social proximity between producers and consumers.

2 Special Report: Selling at Farmers Markets. Ideas and information to make your venture a success. 2009. News \& ideas for local food producers: Growing for Market. Fairplain Publications, Inc. 
Another dimension of the concept of quality in the short supply chains is the principle that the more unique and different is a product, the more scarce and more demanding is the market (Renting et al., 2003). Product differentiation requires the establishment of transparent marketing links around a specific set of quality definitions that are accepted by the parties involved and communicated to the consumer to persuade him/her to pay the price at which the products are offered. Two basic understandings of quality can be distinguished. The first focuses on the relationship between the characteristics of the product, the place of production (natural conditions, cultural or gastronomic traditions, etc.) and the production process (craft, traditional, farm and other foods), which are the key parameters for determining the quality of the product usually resulting in different tastes and appearances. The second group defines quality based on the link between food production and consumption with biological processes, products that meet public commitment to environmental issues and differ in environmentally friendly production methods such as integrated and organic production (Dimitrov and Ivanova, 2017). This includes the understanding of natural and ecological products and healthy and safe products. They attract in part the "romantic pictures" of traditional agriculture, but above all they express the tendencies towards the establishment of multifunctional forms of agriculture contributing to rural nature and landscape. It should be emphasized, however, that there can be no clear distinction, but rather the existence of "hybrid" forms of the various qualitative characteristics.

\section{The example of Bulgaria: farmers' markets in theory and practice}

The Rural Development Programme 2014-2020 of the Republic of Bulgaria in its analytical part states that the local food market in Bulgaria is underdeveloped despite consumer preferences. The lack of producer organizations and the small number of producers' markets are characterized as major weaknesses. Functioning markets sell produce purchased from other places, usually not of local origin, and there is no direct link between a producer and a consumer. At the same time, local food uses informal channels for sales, there are no developed voluntary certification schemes and adequate infrastructure for the existence of farmers' markets. On the other hand, local food markets provide favourable opportunities to overcome problems related to the weak market power of small farms and the provision of quality food for consumers. It should not be forgotten that, due to its small volume, the agricultural market in the country is heavily dependent on the state and trends of the international markets, especially in terms of prices and opportunities for realization.

In the Rural Development Programme 2014-2020 an opportunity has been identified for expanding markets and increasing consumer demand for food products of guaranteed quality and origin, local products, as well as organic products and products produced under high standards for environmental protection and animal welfare. The needs assessment includes conclusions on the need of shortening supply chains, promoting local markets and improving the marketing of agricultural products. A priority area is defined as: improving the competitiveness of primary producers by better integrating them into the agricultural and food chain through quality schemes that add value to agricultural products, promoting local markets and short supply chains, producer groups and organizations and interbranch organizations. Measures are proposed to help farmers access the market and end-users; introducing quality schemes on farms and food producers; support for creation of producer groups, cluster building and cooperation.
There are reglamented opportunies for financial support under various measures, but the focus here will be on activities to promote local markets. The measure 16 - Cooperation includes the submeasure 16.4 - Support for horizontal and vertical cooperation between supply chain actors for the construction and development of short supply chains and local markets. The activities under this measure are intended to help overcome the economic, environmental and other negative effects of fragmentation of small farms through local market associations focusing on small farms (at least $60 \%$ of farms participating in local associations to be small farms as defined in the thematic sub-programme). Assistance will focus on short supply chains and local markets. "Short supply chain" means a supply chain involving a limited number of economic operators committed to cooperating and dedicated to local economic development and close territorial and social relations between producers, processors and consumers. Local markets are "markets within a radius of $75 \mathrm{~km}$ from the place /the agricultural enterprise/ of origin of the product in which there should be carried out both processing and sale to the end user. Support will be provided to organizations implementing collective projects - short supply chain associations or local market associations' projects. Measures will only cover short supply chains that include no more than one intermediary between a farmer and a consumer. Support will also be provided for short supply chains and local market promotion activities in order to inform potential users that a short supply chain or a local market exists and what are the benefits of purchases from a particular short supplies or a specific domestic market. It should also be noticed that till now the measure is not started and this delay hinders a number of risks for future implementation of potential project proposals.

Asurvey (Ninova, 2017) on mechanisms for stimulating microenterprises and farmers' markets among farmers and local market organizers in Bulgaria identifies the main characteristics of the existing agricultural markets, their problems and needs, the relationship between the conditions of the sub-measure 16.4 and the parameters of the potential participants, the infrastructure on the agricultural markets, as well as the opportunities for supporting and financing them in order to develop agricultural markets in the country with positive effects for both producers and consumers. The survey shows that for $3 / 4$ the organizational form is a trade company, and for the rest - a non-profit organization. Markets offer food and non-food products, plant and animal, fresh and processed ones. The distribution of the participants in the agricultural markets embraced in the study shows the following results: Varna $-38 \%$, Plovdiv $-30 \%$, Burgas $-21 \%$, Montana $-11 \%$. Regular participants are $76 \%$ and seasonal $-24 \%$. Up to $75 \mathrm{~km}$ from the market are $72 \%$ of the participants. Registered farmers are $39 \%$ of the participants, retailers $-17 \%$, processors $-42 \%$, non-profit organizations $-2 \% .3 / 4$ of the surveyed markets are organized every week. Depending on the location, they differ in the commercial place - mall, municipal market and other. In most cases, the ownership of the terrain is private, it is used according to the season indoors or outdoors, year-round open or all-year indoor.

The opinions expressed are that the space is satisfactory, narrow and uncomfortable or comfortable. In most cases, there are no volunteers in the organizing team on the market. There are still markets that do not keep administrative records. Communications are mostly done over the phone, in facebook groups or personally during the market. In $3 / 4$ of the cases there are no control tests of the production on the market regardless of the mandatory analyses presented by the participants. There is a definite need to further promote the markets that currently use different channels: facebook, incl. paid advertising, local and national media, print advertising. In most cases, a base site is available, but there is a need to develop a commercial form. 
In most cases, there is a need for more trust-building opportunities in local communities.

There are partnerships with business and non-profit organizations to hold joint events or trade initiatives, but in most cases they are lacking. There is no sponsorship / donation in $3 / 4$ of the cases investigated, but in some cases European and other programmes have provided some funding. The conducted survey shows needs of investment, organizational team and communication, promotion and advertising, trust building and partnerships. The identified challenges for the application of the sub-measure are related to: the requirement for the provision of $50 \%$ self-participation for association, ownership of tangible assets, functioning of the local market union as an economic entity - profits, taxes; communication with municipal and state administration, with private owners; accounting of "standard costs"; building trust and responsibility (Ninova, 2017). The study is a step towards the elaboration of an ordinance for the application of the measure under the Rural development programme and a good experience in regulating the upcoming measure under real conditions. The results show that overcoming the huge challenges before this measure will remain a major issue and will question the search for such support and its effectiveness.

Below, some examples will be presented as a good practice for establishing a new type of relationship between producers and consumers of farm products.

Farmers' markets "Hrancoop" define their mission as providing "access to clean food" and the motto is "personally by the producers". Producers are small family farms that offer almost entirely their own production or cooperate with neighbouring farms for the market presence. Most are certified organic, but all are for clean food, nature conservation, and people's health. At least once a month, thematic events are organized - about food, healthy lifestyle, culture, etc. The markets have a distinct part for children and eco-workshops for the promotion of sustainable lifestyles. According to Hrankoop, short supply chains have the potential to contribute to more sustainable food systems, rural development and healthier communities through: health and well-being, environmental benefits, social benefits, economic benefits, lasting change in food culture and improving the quality of life in rural areas.

The LocalFood.bg Foundation offers a series of incentive initiatives for the development of the farmers' markets in the country and it has published on its website a short guide to organizing the agricultural markets (13.07.2017), presenting the first seven steps for launching a farm market: planning, attracting, location, rules, legality, and support, accompanied by a set of documents necessary for the successful functioning of a farm market in the country, incl. a labeling guide. It is remarkable that here is the experience gained from organizing the farmers' market in Plovdiv, which is freely shared and inspired by farmers and processors for good management and food safety. The foundation encourages micro and small entrepreneurs with different activities and projects.

Another interesting practice is 'farmhopping', which evolves from on-line marketing and home delivery, emphasizing the "checked" quality of the products offered: each farm practices sustainable agriculture and production and presents documents on the products it offers; additional control is performed through various measurements and studies of each delivery; a downstream control and feedback system is in place. Farmhopping guarantees the origin of the products with their name.

In 2017, an exhibition of farmer's food was presented to the Ministry of Agriculture, Food and Forestry in Sofia by Foundation for organic agriculture "Bioselena" under the project "Weekly festival from our farm - with love for you", which is being carried out with the financial support of the Sofia
Municipality and the Europe 2017 Programme in partnership with the Bulgarian Society for the Protection of Birds and the Sredets Region.

A common feature for all those is the experience of organizing different events and engaging users. Moreover, local food begins to show interest in even the big commercial chains that are starting to look for local, authentic and healthy foods. It should be emphasized, however, that it is not uncommon to speculate on prices and quality which, along with compliance with legal requirements, is also the main challenge for the future functioning of farmers' markets and building trust in consumers and society.

In order to respond adequately to modern realities, trends and challenges in the development of farmers'markets in Bulgaria and to promote and expand them as a social and economic initiative, actions are needed in two main directions - both for producers and for consumers - with broad public support, clear legal requirements and their compliance by all, as well as local support related to infrastructure, funding and awareness.

\section{Conclusion}

Farmers' markets are particularly appropriate for small producers or for experimentation with small volumes of new products that would be at risk for large industries. The benefits of the farmer markets can be seen in several aspects: for the consumer (a wider choice of fresh and affordable food and the opportunity to meet friends), for the farmer (better sales opportunities, diversification and consumer contact than other channels - both in terms of prices and in terms of synergies and acquisition of business skills); for the society (link between production and consumption, building clustered societies, promoting and preserving local productions, traditions and culture, etc.). In addition, farmers' markets contribute to ensuring diversity in agricultural production, overcoming strong specialization and food security. The overall food system is so complex that many political and economic factors lead to a reduction in the number of small and family farms, but it is the farmers' markets that provide the opportunity for consumer choice to build more independent local communities and local businesses, as well as safer food systems. Farmers' markets can be a successful business model with a potential to contribute to sustainable rural development. The question how to be supported by state and European funds should be carefully treated because it has at least three faces - the first one is connected to the overregulation of some requirements, the second one is the risk of providing financial support to initiatives which do not have the needed potential and capacity to implement such projects, the third one is related to the need of raising information, awareness and motivation among consumers, building trust and new relations in local communities and society as a whole.

\section{Acknowledgments}

This article is presented as part of the project "Farmers'markets - a sustainable business model for rural development" implemented according to the Plan of scientific and research activities in University of agribusiness and rural development - Bulgaria.

\section{References}

BARBERA, F. - DAGNES, J. 2016. Building alternatives from the bottom-up: The case of alternative food networks. In Agriculture and Agricultural Science Procedia, vol. 8, 2016, pp. 324-331.

BOS, E. - OWEN, L. 2016. Virtual reconnection: The online spaces of alternative food networks in England. In Journal of Rural Studies, vol. 45, 2016, pp. 1-14. 
CASSIA, F. - UGOLINI, M. - BONFANTI, A. - CAPPELLARI, C. 2012. The perceptions directions for customer-company-territory interaction (CCTI). In Procedia - Social and Behavioral Sciences, vol. 58, pp. 1008-1017.

DIMITROV, D. - IVANOVA, M. 2017. Trends in organic farming development in Bulgaria: applying circular economy principles to sustainable rural development. In Visegrad Journal on Bioeconomy and Sustainable Development, vol. 6, 2017, no. 1, pp. 10-16.

Farmers' markets "Hrancoop": http://pazari.hrankoop.com/

Farmhopping: https://farmhopping.com/

Foundation for Organic Agriculture Bioselena: http://www.bioselena.com/

Foundation LocalFood.bg: https://localfood.bg/

MAINVILLE, D. 2010. Foundations for a successful farmers market. Produced by Communications and Marketing. Virginia : College of Agriculture and Life Sciences, Virginia Polytechnic Institute and State University, 2010, pp. 448-502.

MATACENA, R. 2016. Linking alternative food networks and urban food policy: a step forward in the transition towards a sustainable and equitable food system? In International Review of Social Research, vol. 6, 2016, no. 1, pp. 49-58.

NINOVA, M. 2017. European mechanisms for stimulation of microenterprises and farmers' markets. Presentation of the Ministry of agriculture, food and forestry at the Conference "Future for local food", 22 February 2017, Plovdiv, International agricultural exhibition "Agra": http://localfood-bg.wixsite.com/old-localfoodbg/ conference-agra/

PASCUCCI, S. - DENTONI, D. - LOMBARDI, A. - CEMBALO, L. 2016. Sharing values or sharing costs? Understanding consumer participation in alternative food networks. NJAS. In Wageningen Journal of Life Sciences, vol. 78, 2016, pp. 47-60.

PIERSON, J. 2009. Top 10 rules of market displays. News \& ideas for local food producers: Growing for Market. Fairplain Publications, Inc.
RENTING, H. - MARSDEN, T. K. - BANKS, J. 2003. Understanding alternative food networks: exploring the role of short food supply chains in rural development. In Environment and Planning A, vol. 35, 2003, pp. 393-411.

RURAL development program of the Republic of Bulgaria 2014-2020.

SPECIAL REPORT: Selling at Farmers Markets. Ideas and information to make your venture a success. 2009. News \& ideas for local food producers: Growing for Market. Fairplain Publications, Inc.

STARTING a new farmers market. 2005. D. Jolly (Ed.). The Farmers Market Management Series, vol. 1, 2005. UC Small Farm Center.

TOZER, C. E. 2013. Alternative food networks and value creation: The case of farmers markets in New Zealand. Thesis in Massey University.

WOLF, M.M. - SPITTLER, A. - AHERN, J. 2005. A profile of farmers' market consumers and the perceived advantages of produce sold at farmers' markets. In Journal of Food Distribution Research, vol. 36, 2005, no. 1, pp. 192-201.

\section{Contact address}

Assoc. Prof. Ekaterina Arabska, Ph.D.

University of agribusiness and rural development, Plovdiv

78, Dunav Blvd., Plovdiv 4003, Bulgaria

GSM: +359 $896778586 ;+359882009578$

e-mail: earabska@uard.bg, katya.arabska@gmail.com 